\title{
The Sand Rat, Psammomys obesus, Develops Type 2 Diabetic Retinopathy Similar to Humans
}

\author{
Tounès Sä̈di, ${ }^{1,2}$ Sihem Mbarek, ${ }^{2}$ Samy Omri, ${ }^{3}$ Francine Behar-Cohen, ${ }^{3}$ \\ Rafika Ben Chaouacha-Chekir, ${ }^{2}$ and David Hicks ${ }^{1}$
}

Purpose. Diabetic retinopathy (DR) is a leading cause of blindness, yet pertinent animal models are uncommon. The sand rat (Psammomys obesus), exhibiting diet-induced metabolic syndrome, might constitute a relevant model.

Methods. Adult $P$. obesus $(n=39)$ were maintained in captivity for 4 to 7 months and fed either vegetation-based diets $(n=$ $13)$ or standard rat chow $(n=26)$. Although plant-fed animals exhibited uniform body weight and blood glucose levels over time, nearly $60 \%$ of rat chow-raised animals developed diabetes-like symptoms (test group). Animals were killed, and their eyes and vitreous were processed for immunochemistry.

RESUlts. Compared with plant-fed animals, diabetic animals showed many abnormal vascular features, including vasodilation, tortuosity, and pericyte loss within the blood vessels, hyperproteinemia and elevated ratios of proangiogenic and antiangiogenic growth factors in the vitreous, and blood-retinal barrier breakdown. Furthermore, there were statistically significant decreases in retinal cell layer thicknesses and densities, accompanied by profound alterations in glia (downregulation of glutamine synthetase, glutamate-aspartate transporter, upregulation of glial fibrillar acidic protein) and many neurons (reduced expression of protein kinase $\mathrm{C} \alpha$ and $\mathrm{C} \xi$ in bipolar cells, axonal degeneration in ganglion cells). Cone photoreceptors were particularly affected, with reduced expression of short- and mid-/long-wavelength opsins. Hypercaloric diet nondiabetic animals showed intermediate values.

Conclusions. Simple dietary modulation of $P$. obesus induces a rapid and severe phenotype closely resembling human type 2 DR. This species presents a valuable novel experimental model for probing the neural (especially cone photoreceptor) pathogenic modifications that are difficult to study in humans and for screening therapeutic strategies. (Invest Ophthalmol Vis Sci. 2011;52:8993-9004) DOI:10.1167/iovs.11-8423

$\mathrm{D}$ iabetic retinopathy (DR) is the fifth leading cause of blindness worldwide and the third in terms of retinal disorders ( $\sim 170$ million, World Health Organization). It constitutes the

From the ${ }^{1}$ Département de Neurobiologie des Rythmes, Institut des Neurosciences Cellulaires et Intégratives, Strasbourg, France; ${ }^{2}$ Université de la Manouba, Unité de recherche d'Ecophysiologie Générale et Comparée, Institut Supérieur de Biotechnologie Sidi Thabet, Ariana, Tunisia; and ${ }^{3}$ INSERM U872, Physiopathology of Ocular Diseases: Therapeutic Innovations, Paris, France

Supported by the Fritz Tobler Foundation.

Submitted for publication August 16, 2011; revised September 24 and 30, 2011; accepted October 1, 2011

Disclosure: T. Saïdi, None; S. Mbarek, None; S. Omri, None; F. Behar-Cohen, None; R.B. Chaouacha-Chekir, None; D. Hicks, None

Corresponding author: David Hicks, Département de Neurobiologie des Rythmes, CNRS UPR 3212, Institut des Neurosciences Cellulaires et Intégratives, 5 rue Blaise Pascal, 67084 Strasbourg Cedex, France photoreceptor67@hotmail.com. leading cause of vision loss for working-age persons in developed countries. ${ }^{1}$ DR has been viewed principally as a microvascular disease, and hyperglycemia induces the disruption of cell junctions within the retinal endothelium, thickening of basement membranes and pericyte loss. ${ }^{2}$ Vessels become leaky and acellular, circulation is compromised leading to the formation of ischemic zones, and exudation from the capillaries contributes to macular edema. ${ }^{3}$ However, many studies have indicated that abnormal visual function, such as decreased contrast sensitivity ${ }^{4}$ or color vision defects, ${ }^{5-7}$ actually precede clinically detectable signs of retinopathy, suggesting that vascular abnormalities are not the first events to occur in DR.

Numerous rodent models of DR exist, with varying degrees of similarity to the human disease. No single animal model recapitulates all the neural and vascular complications associated with DR, especially the late-stage proliferative form, PDR. ${ }^{8}$ Animal models can be classified as drug-induced, as with the destruction of pancreatic beta cells by streptozotocin (SZT) ${ }^{8,9}$; genetic, as with the widely used Ins $2^{\text {akita }}$ mouse $\operatorname{strain}{ }^{10}$; and spontaneously occurring diabetes. ${ }^{11}$ This last category includes the sand rat $P$. obesus, long known to develop metabolic stress syndrome in captivity. In contrast to animals maintained on a natural plant-rich diet, when reared on a high-calorie regimen many animals exhibit hallmark features of type 2 diabetes. ${ }^{12}$ The similarity between metabolic, physiological, and endocrine changes in this species and those occurring in human type 2 diabetes makes it a highly relevant animal model with which to understand the pathogenesis of this condition. ${ }^{13}$

Aside from a single study on tyrosine hydroxylase levels during diabetes, ${ }^{14}$ retinal modifications occurring in this species are unknown. We reasoned that, given the other numerous similarities between type 2 diabetes in Psammomys and humans, the rodents may also develop DR and serve as a novel model for unraveling the complex pathogenesis in this blinding disease. The extensive morphologic and immunochemical studies presented here support this hypothesis.

\section{Materials AND Methods}

\section{Experimental Animals}

All animal experimentation adhered to the ARVO Statement for the Use of Animals in Ophthalmic and Vision Research and abided by national and local laws of ethical conduct. Young adult $P$. obesus were captured in southern Tunisia using baited traps, transferred to animal facilities, and maintained under cyclic lighting conditions (12 hours white light [ $\sim 300$ lux $] / 12$ hours dark) with free access to food and water. Data presented in this study came from two independent field excursions, the first concerning 15 animals and the second concerning 26 animals. Male animals were separated into two groups. The low calorie diet control group ( $n=5$ from the first capture, $n=8$ from the second capture; $n=13$ total) was raised on a natural diet (ND) and was fed only halophilic plants, rich in water and mineral salts $(0.4 \mathrm{kcal} / \mathrm{g}$ wet weight). The other animals ( $n=10$ from the first capture, $n=16$ from 
the second capture; $n=26$ total) received a standard laboratory rat chow feed (3.3 kcal/g; Purina). Both groups were followed up for 4 months (first capture) or 7 months (second capture), with measurements of their body weight, plasma glucose (One Touch Ultra Blood Glucose Monitoring System 20247; LifeScan, Inc., Milipitas, CA), and hematocrit every 5 days. Based on weight and glucose measurements (see Results), a total of 15 animals from the hypercaloric groups ( $n=$ 5 from the first capture, $n=10$ from the second capture) were considered diabetic (blood glucose levels $>200 \mathrm{mg} / \mathrm{dL}$ after 6 weeks of diet) and termed high-protein diet diabetic (HDD). The remaining hypercaloric animals ( $n=5$ from the first capture, $n=6$ from the second capture; $n=11$ total) were classified as high-protein diet nondiabetic (HDnD). At the end of the experimental periods ( 4 and 7 months, respectively, for the two series), animals were euthanized by $\mathrm{CO}_{2}$ inhalation and decapitation. Eyes were either fixed in $4 \%$ paraformaldehyde in PBS $(0.01 \mathrm{M}, \mathrm{pH} 7.4)$ for 12 hours at $4^{\circ} \mathrm{C}$ or the retinas and vitreous bodies were dissected free under a binocular microscope and snap frozen in liquid nitrogen. Samples were processed for sec- tioning on a cryostat (CM $3050 \mathrm{~S}$; Leica, Wetzlar, Germany) using standard protocols. For flat-mounted preparations, after fixation as described above, the eyeballs were opened at the limbus, and the cornea and lens were discarded. The retinas were carefully separated from the posterior eyecup composed of the retinal pigment epithelium (RPE), choroid, and sclera, and both tissues were washed in PBS. Radial incisions were made in the retinas and eyecups to permit flattening.

\section{Immunohistochemistry}

Sections were processed for immunohistochemistry using conventional procedures. ${ }^{15}$ Primary antibodies are listed in Table 1 and were diluted in saturation buffer (PBS containing $0.1 \%$ bovine serum albu$\min$ and $0.1 \%$ Tween 20) and left overnight at $4^{\circ} \mathrm{C}$. Sections were washed and then incubated with the appropriate secondary antibodies, either goat anti-rabbit or anti-mouse IgG-conjugated antibodies coupled with Alexa 594 or Alexa 488 (Molecular Probes Ltd., Eugene, OR) diluted 1:400. Cell nuclei were stained with 4,6-di-amino-phenyl-

TABLE 1. Antibodies Used in Immunohistochemistry and Western Blot Analysis

\begin{tabular}{|c|c|c|c|c|}
\hline Antibody/Antigen & Type & Retinal Staining & Dilution & Manufacturer/Supplier \\
\hline VEGF & Monoclonal (mouse) & - & WB $0.1 \mu \mathrm{g} / \mathrm{mL}$ & $\begin{array}{l}\text { Santa Cruz Biotechnology, } \\
\text { Santa Cruz, California }\end{array}$ \\
\hline PEDF & Polyclonal (rabbit) & - & WB $0.1 \mu \mathrm{g} / \mathrm{mL}$ & $\begin{array}{c}\text { Kind gift of Joyce Tombran-Tink, } \\
\text { Pennsylvania State College } \\
\text { of Medicine, Hershey, PA }\end{array}$ \\
\hline$\alpha$-Smooth muscle actin & Monoclonal (mouse) & Pericytes (blood vessels) & $\mathrm{IHC} 1 \mu \mathrm{g} / \mathrm{mL}$ & $\begin{array}{l}\text { Sigma Aldrich Life Sciences, } \\
\text { Cergy Pontoise, France } \\
\text { (A7607) }\end{array}$ \\
\hline GFAP (whole protein from cow) & Polyclonal (rabbit) & Astrocytes/Müller glia & $\begin{array}{l}\text { IHC } 2 \mu \mathrm{g} / \mathrm{mL} \\
\text { WB } 0.2 \mu \mathrm{g} / \mathrm{mL}\end{array}$ & $\begin{array}{l}\text { DAKO A/S, Glostrup, } \\
\text { Denmark (Z 0334) }\end{array}$ \\
\hline $\begin{array}{l}\text { Glutamine synthetase } \\
\text { (mouse peptide) }\end{array}$ & Monoclonal (mouse) & Glia & $\begin{array}{l}\text { IHC } 2 \mu \mathrm{g} / \mathrm{mL} \\
\text { WB } 0.2 \mu \mathrm{g} / \mathrm{mL}\end{array}$ & Millipore (mAb 302) \\
\hline GLAST-1 (rat C-terminal peptide) & Polyclonal (rabbit) & Glia & $\begin{array}{l}\text { IHC } 2 \mu \mathrm{g} / \mathrm{mL} \\
\text { WB } 0.2 \mu \mathrm{g} / \mathrm{mL}\end{array}$ & $\begin{array}{l}\text { Alpha Diagnostic International } \\
\text { (GLAST 11-S) }\end{array}$ \\
\hline Neurofilament (200 kDa) & Monoclonal (mouse) & RGC, HC & $\mathrm{IHC} 1 \mu \mathrm{g} / \mathrm{mL}$ & Sigma (N-20) \\
\hline p-PKC $\zeta$ (human peptide) & Polyclonal (rabbit) & Rod and cone ON BC & IHC $5 \mu \mathrm{g} / \mathrm{mL}$ & $\begin{array}{l}\text { Santa Cruz Biotechnology, } \\
\text { sc-12894-R (Thr 410) }\end{array}$ \\
\hline $\operatorname{PKC} \alpha$ & Monoclonal (mouse) & Rod and cone ON BC & $\begin{array}{l}\text { WB } 0.5 \mu \mathrm{g} / \mathrm{mL} \\
\text { IHC } 5 \mu \mathrm{g} / \mathrm{mL}\end{array}$ & $\begin{array}{l}\text { Santa Cruz Biotechnology, } \\
\text { (H-7) sc-8393 }\end{array}$ \\
\hline Parvalbumin & Monoclonal (mouse) & $\mathrm{HC}$ & $\begin{array}{l}\text { WB } 0.5 \mu \mathrm{g} / \mathrm{mL} \\
\text { IHC } 1 \mu \mathrm{g} / \mathrm{mL}\end{array}$ & Sigma P3088 \\
\hline Synaptophysin (rat protein) & Monoclonal (mouse) & $\begin{array}{l}\text { Synapses (plexiform } \\
\text { layers) }\end{array}$ & $\begin{array}{l}\text { IHC } 1 \mu \mathrm{g} / \mathrm{mL} \\
\text { WB } 0.1 \mu \mathrm{g} / \mathrm{mL}\end{array}$ & $\begin{array}{l}\text { Santa Cruz Biotechnology, } \\
\text { sc-12737 (SVP38) }\end{array}$ \\
\hline Rhodopsin (Rho4D2) & Monoclonal (mouse) & $\mathrm{ROS}+++$ and $\mathrm{RCB}+$ & $\begin{array}{l}\text { IHC } 1 \mu \mathrm{g} / \mathrm{mL} \\
\text { WB } 0.1 \mu \mathrm{g} / \mathrm{mL}\end{array}$ & $\begin{array}{l}\text { Kind gift of Robert Molday, } \\
\text { University of British } \\
\text { Columbia, Vancouver, BC, } \\
\text { Canada }\end{array}$ \\
\hline $\begin{array}{l}\text { MW cone opsin } \\
\text { (mouse peptide) }\end{array}$ & Polyclonal (rabbit) & COS (MW cones) & $\begin{array}{l}\text { IHC } 1 \mu \mathrm{g} / \mathrm{mL} \\
\text { WB } 0.1 \mu \mathrm{g} / \mathrm{mL}\end{array}$ & $\begin{array}{l}\text { Kind gift of Cheryl Craft, } \\
\text { Doheny Eye Institute, } \\
\text { University of Southern } \\
\text { California, Los Angeles, } \\
\text { California }\end{array}$ \\
\hline $\begin{array}{l}\text { SW cone opsin (mouse } \\
\text { peptide) }\end{array}$ & Polyclonal (rabbit) & COS (SW cones) & $\begin{array}{l}\text { IHC } 1 \mu \mathrm{g} / \mathrm{mL} \\
\text { WB } 0.1 \mu \mathrm{g} / \mathrm{mL}\end{array}$ & Kind gift of Cheryl Craft \\
\hline Peripherin (rat protein) & Monoclonal (mouse) & OS & $\mathrm{IHC} 1 \mu \mathrm{g} / \mathrm{mL}$ & Kind gift of Robert Molday \\
\hline Arrestin (cow protein) & Polyclonal (rabbit) & OS, CB & $\mathrm{IHC} 1 \mu \mathrm{g} / \mathrm{mL}$ & $\begin{array}{l}\text { Kind gift of Igal Gery, } \\
\text { National Institutes of } \\
\text { Health, Bethesda, Maryland }\end{array}$ \\
\hline Recoverin & Polyclonal (rabbit) & $\mathrm{OS}, \mathrm{CB}, \mathrm{BC}$ & $\mathrm{IHC} 1 \mu \mathrm{g} / \mathrm{mL}$ & $\begin{array}{l}\text { Kind gift of Alexander } \\
\text { Dizhoor, Northwestern } \\
\text { University, Chicago, Illinois }\end{array}$ \\
\hline $\mathrm{G} \alpha \mathrm{t} 1$ (rod transducin) & Polyclonal (rabbit) & ROS, RCB & IHC $1 \mu \mathrm{g} / \mathrm{mL}$ & $\begin{array}{l}\text { Santa Cruz Biotechnology, } \\
\text { K-20 sc-389 }\end{array}$ \\
\hline $\mathrm{G} \alpha \mathrm{t} 2$ (cone transducin) & Polyclonal (rabbit) & COS, CCB & IHC $1 \mu \mathrm{g} / \mathrm{mL}$ & $\begin{array}{l}\text { Santa Biotechnology Cruz, } \\
\text { I-20 sc-390 }\end{array}$ \\
\hline
\end{tabular}

The table shows antibody/antigen type, cellular localization within the retina (if used in IHC), working dilution for IHC and WB, and commercial origin or reference. WB, Western blot; IHC, immunohistochemistry; BC, bipolar cells; (C/R)OS, (cone/rod) outer segments; (C/R)CB, (cone/rod) cell bodies; HC, horizontal cells; RGC, retinal ganglion cells. 
indolamine (DAPI; Sigma Aldrich Life Sciences, Cergy Pontoise, France) diluted 1:500. Incubation was performed at room temperature for 2 hours, and sections were washed thoroughly in PBS and coverslipped. Retinal and posterior eyecup wholemount immunohistochemistry was performed as described previously. ${ }^{15}$ Some tissues were incubated in lectin from Bandeiraea simplicifolia directly conjugated to tetrarhodamine isothiocyanate $(25 \mu \mathrm{g} / \mathrm{mL}$; Sigma Aldrich Life Sciences), or to phalloidin- tetrarhodamine isothiocyanate $(100 \mu \mathrm{g} / \mathrm{mL}$ Invitrogen-Molecular Probes, Eugene, OR) for 4 hours at room temperature. Slides were examined with a fluorescence microscope (Optiphot 2; Nikon, Melville, NY), and images were captured using image analysis software (NIS-Elements BR 3.0; Nikon) or a confocal microscope (LSM510 version 2.5; Carl Zeiss Meditec, Jena, Germany). Photographs were taken with identical exposure times between control and treated specimens. Any graphics editing of images (Photoshop; Adobe, San Jose, CA) was performed using identical parameters between the two sets. Tissues from a minimum of three animals per group (ND, HDnD, and HDD) were examined for each condition.

\section{Western Blot Analysis}

Western blot analysis was performed on proteins extracted from entire vitreous and retinas ( $n=3$ per group), as described. ${ }^{15}$ After incubation on ice for 30 minutes, proteins were suspended in Laemmli buffer and separated by SDS-PAGE ( $4 \%-10 \% ; 40-50 \mu \mathrm{g}$ protein/lane; total protein concentrations were initially determined using the Bradford colorimetric assay) and then transferred onto a polyvinylidene fluoride membrane. Membranes were incubated with primary antibodies (Table 1) overnight at $4{ }^{\circ} \mathrm{C}$ under agitation, washed, and incubated with corresponding secondary antibodies coupled to horseradish peroxidase (1:10,000; Jackson ImmunoResearch Laboratories, West Grove, PA). Immunoreactive bands were detected by chemiluminescence (Immobilon Western; Millipore, Bedford, MA). Relative abundance was quantified by scanning densitometry (ImageJ software, developed by Wayne Rasband, National Institutes of Health, Bethesda, MD; available at http://rsb.info.nih.gov/ij/index.html), and expressed relative to tubulin immunoreactive bands in the same blots (detected after membrane stripping and reprobing with monoclonal antitubulin antibody, diluted 1:10,000 [Jackson ImmunoResearch Laboratories]). Experiments were performed on extracts from a minimum of three retinas from separate animals for each group.

\section{Measurement of Retinal Vasculature}

The entire vasculature, from the optic nerve head toward the periphery, was visualized on retinal flatmounts under a fluorescence microscope (Optiphot 2; Nikon). The entire field was mapped using rectangular grids $\left(810.87 \mu \mathrm{m}^{2}\right)$, and the surface was divided into nine concentric zones (see Results; Fig. 3E). The retinal vascular caliber was measured along the entire length of each major vessel, at 10 regularly spaced points $(\sim 3 \mu \mathrm{m})$ for each rectangle, for three separate retinas from ND, HDnD, and HDD animals. We further measured the number of branch points in the most peripheral zone (lying beyond zone 9) for three retinas from each ND and HDD group, averaged per square millimeter.

\section{Trypsin Digestion}

To isolate the retinal vascular bed from fixed retinas, we followed published procedures. ${ }^{16}$ Quantification of acellular cordlike capillaries was performed using the criteria described by these authors, under $40 \times$ microscope objectives, using a $100 \times 100 \mu \mathrm{m}$ grid superimposed over 10 random fields of HD and HDD preparations. Measurement of major vessel thickness was performed as described, beginning at the widest (central) end of isolated vessels.

\section{Cell Counting}

The density of cell nuclei and cell layer thickness was determined for each condition (three fields of each of three animals per group) by light microscope examination of retinal sections. Images were obtained within the posterior retina, within $1 \mathrm{~mm}$ of the optic nerve head. Cell layer thickness and number of nuclei per layer were calculated within a standard rectangle placed across captured images, equivalent to an area measuring $0.07 \mathrm{~mm}^{2}{ }^{17}$

\section{Statistical Analysis}

Results are expressed as mean $\pm \mathrm{SD}$. Comparisons of the two groups (cell counting and Western blot analyses) were performed using factorial analysis of variance (ANOVA) followed by post hoc Tukey HSD test. $P<0.05$ was considered statistically significant. Calculations were performed using statistical analysis software (Statistica 8.0; StatSoft, Maisons-Alfort, France). For vessel parameter analysis, we used twoway ANOVA for independent and repeated measures, followed by post hoc Tukey HSD test.

\section{Results}

\section{Development of Obesity and Hyperglycemia}

Figure 1 depicts results from the second capture, involving 24 animals. Whereas body mass and blood glucose levels re-

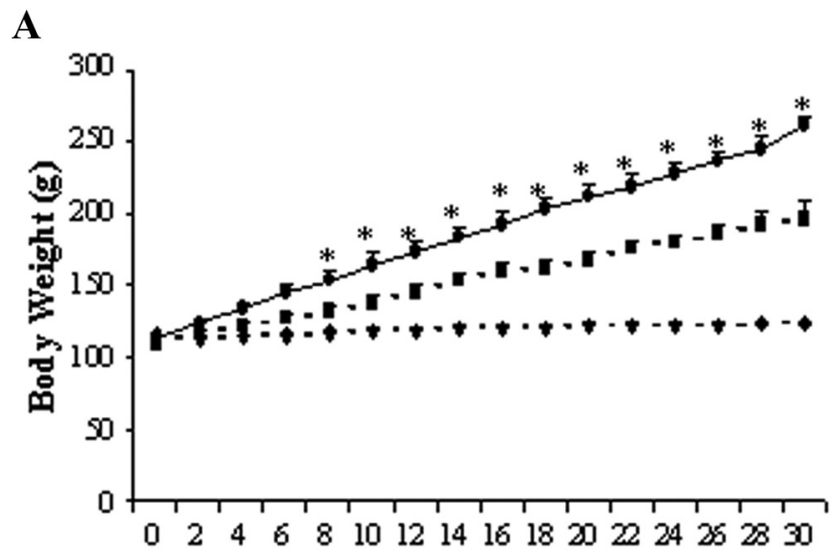

B

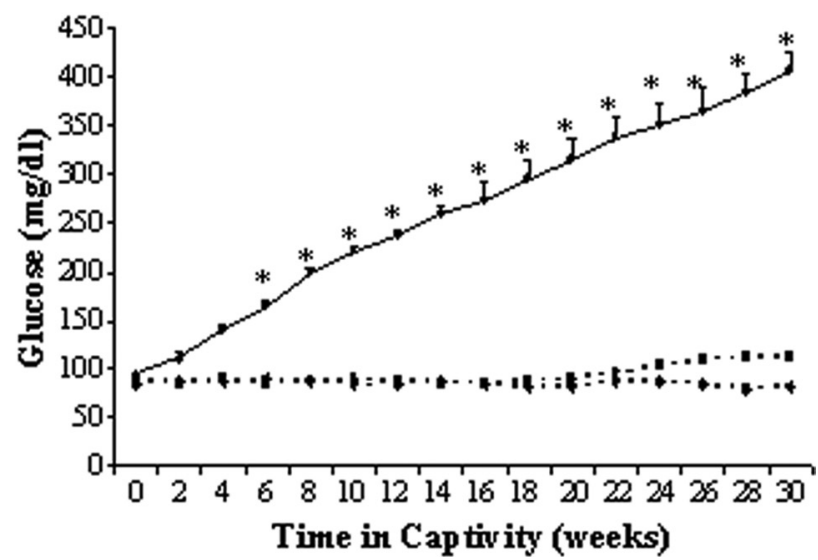

Figure 1. Body weight and blood glucose evolution in $P$. obesus during 7 months of captivity. Although animals reared on natural halophilic plants ( $n=8$, ND, filled diamonds) remained stable throughout the entire period, of the 16 animals reared on hypercaloric diets (standard rat chow), 10 showed steady increases in weight (diabetic, HDD, filled circles) (A) and glucose levels (B). The remaining six animals demonstrated weight gain under hypercaloric conditions (HDnD, filled squares) but did not exhibit increased blood glucose levels relative to ND animals. Data are expressed as mean \pm SD. Significant differences were determined by ANOVA ( $P<0.05)$. 
Table 2. Vitreal Protein, Proangiogenic, and Antiangiogenic Growth Factor Levels in ND and HDD P. obesus

\begin{tabular}{|c|c|c|}
\hline & $\begin{array}{c}\text { ND } \\
(n=8)\end{array}$ & $\begin{array}{c}\text { HDD } \\
(n=10)\end{array}$ \\
\hline $\begin{array}{l}\text { Vitreous protein levels, } \mu \mathrm{g} / \mu \mathrm{L} \\
\text { Mean VEGF/PEDF ratio }\end{array}$ & $\begin{array}{c}0.32 \pm 0.01 \\
0.239 \pm 0.007\end{array}$ & $\begin{aligned} 0.71 & \pm 0.03^{*} \\
71.364 & \pm 7.686^{*}\end{aligned}$ \\
\hline
\end{tabular}

Values are mean $\pm \mathrm{SD}$. Measurement of total soluble protein content of vitreous isolated from ND and HDD animals showed highly significant differences, with 2.2-fold greater levels in diabetic samples As calculated from Western blots using anti-VEGF and anti-PEDF, ratios of the two proteins were calculated from ND $(n=8)$ and HDD $(n=$ 10) individual vitreal samples.

${ }^{*} P<0.001$.

mained stable over time in captivity in plant-fed animals (ND; $n=8$ ), many animals raised on standard rat chow (total $n=$ 16) became obese and developed hyperglycemia (HDD; $n=$ 10). Six animals on high-calorie diets did not show increased blood glucose levels (except slight increases during the final month of captivity, which were not significantly different from the ND values), although they showed intermediate values of weight gain (HDnD; Fig. 1). Values for body weight (Supplementary Table S1, http://www.iovs.org/lookup/suppl/ doi:10.1167/iovs.11-8423/-/DCSupplemental) and blood glucose (Supplementary Table S2, http://www.iovs.org/lookup/suppl/ doi:10.1167/iovs.11-8423/-/DCSupplemental) for each animal as a function of time in captivity are given in Supplementary Data, http://www.iovs.org/lookup/suppl/doi:10.1167/iovs.11-8423/-/ DCSupplemental. Although ND animals exhibited a stable weight of $\sim 115 \mathrm{~g}$ throughout the experimental period, HDD animals gained 10 to $20 \mathrm{~g}$ per month to reach $\sim 250 \mathrm{~g}$ at 7 months. HDnD animals gained $\sim 10 \mathrm{~g}$ per month to reach $\sim 180 \mathrm{~g}$ in the same period. ND animals had $\sim 80 \mathrm{mg} / \mathrm{dL}(5 \mathrm{mM})$ blood glucose levels throughout the time in captivity, whereas HDD animals showed permanently increasing concentrations with monthly increments of $\sim 100 \mathrm{mg} / \mathrm{dL}$ to reach $400 \mathrm{mg} / \mathrm{dL}(25$ $\mathrm{mM}$ ) by 7 months (Fig. 1B). Hematocrit values for the three groups did not vary significantly over the course of captivity or between groups (mean $44 \%$ for both; data not shown). Results from the first capture were largely similar, with ND, HDnD, and HDD groups ( $n=5$ in each group) maintained for 4 months (Supplementary Fig. S1, Table S1, http://www.iovs. org/lookup/suppl/doi:10.1167/iovs.11-8423/-/DCSupplemental). Although captivity was shorter, the HDD group increased body weight by approximately $80 \%$ and blood glucose by $~ 350 \%$ compared with starting values (ND group $=10 \%$ weight gain, $0 \%$ glucose increase; $\mathrm{HDnD}$ group $=40 \%$ weight gain, $0 \%$ glucose increase over same period).

\section{Vitreal Protein Analysis in P. obesus}

Total protein concentrations in HDD vitreous were approximately 2.2-fold greater than those of ND animals, with mean values of 0.32 and $0.71 \mu \mathrm{g} / \mu \mathrm{L}$ in ND and HDD groups, respectively (Table 2). Quantitative Western blots of vascular endothelial growth factor (VEGF) and pigment epithelium derived growth factor (PEDF) from each group showed highly significant statistical differences in both cases, with VEGF values $\sim 8$-fold higher, and PEDF values $\sim 100$-fold lower, in HDD animals (Fig. 2). VEGF/PEDF ratios calculated from these data showed very large differences (up to 340-fold) between the two groups (Table 2). VEGF and PEDF concentrations were not studied in HDnD animals.

\section{Vascular and Retinal-Blood Barrier Modifications in Diabetic P. obesus}

Examination of isolectin-labeled blood vessels in flat-mounted whole retinas showed a clear demarcation into large retinal vessels (arteries and veins) and retinal capillaries (Fig. 3). Although blood vessels in the ND group showed a regularly branching uniform aspect (Fig. 3A), HDD retinas showed a variety of abnormal features: vessels displayed an irregular width with alternating constrictions and dilations (Fig. 3B) as well as focal vascular sprouts with blind ends (Fig. 3C) and balloon-like swellings resembling microaneurysms (Fig. 3D). Quantitative measures of major blood vessel diameter as a function of distance from the optic nerve head (Fig. 3E) showed that mean values for HDD were always higher than for ND retinas and were statistically significantly different in the midperiphery (Fig. 3F). Mean values for HDnD blood vessels were intermediate but were not statistically significantly different from ND values (Fig. 3F). Quantification of branch points in the far peripheral capillaries also showed highly significant differences between ND $\left(119.7 \pm 19.2 / \mathrm{mm}^{2}\right)$ and HDD $\left(225.5 \pm 22.8 / \mathrm{mm}^{2} ; 88 \%\right.$ increase $\left.P<0.001\right)$. Similar analyses of HDnD retinas revealed intermediate values, which, although higher than plant-fed animals, did not attain statistical significance $\left(190.7 \pm 29.9 / \mathrm{mm}^{2} ; P=0.059\right)$. Analysis of the retinal vasculature after trypsin digestion revealed a regular network of uniform capillaries in ND tissue (Fig. 3G) but the presence of thin cord-like acellular strands in HDD samples (Fig. $3 \mathrm{H}$ ). Similar measures of major blood vessel diameter as performed in intact flat-mounted retinas also showed differences in ND and HDD thickness in isolated vascular net preparations (Fig. 3I). Furthermore, counting of acellular strands in these trypsin digests confirmed the large differences between ND and HDD samples (Fig. 3J). Trypsin digest experiments were not performed for HDnD retinas.

Staining of ND retinal flat-mounts with isolectin (to outline vessels) and smooth muscle actin antibody (to label pericytes) revealed that ND blood vessels were decorated densely with pericytes (Figs. 4A, 4B). In contrast, although HDD retinas showed extensive isolectin staining of vessels (Fig. 4C), there was almost complete absence of pericytes (Fig. 4D). At the level of the blood-retina barrier within the posterior pole, phalloidin staining of f-actin bundles within flat-mounted ND eyecups revealed a highly regular honeycomb-like aspect of the RPE monolayer, formed of tightly linked hexagonal cells cou-
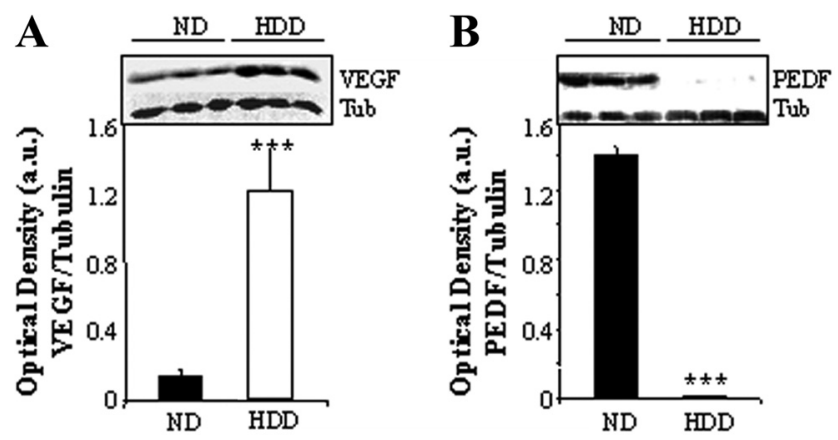

FIGURE 2. Proangiogenic and antiangiogenic growth factors in the vitreous of control and diabetic retinas. (A) VEGF-immunoreactive bands in vitreous samples from three control (ND, left) and three diabetic (HDD, right) animals. (B) PEDF-immunoreactive bands in vitreous samples from three control (ND, left) and three diabetic (HDD, right) animals. The bands were analyzed by densitometry and normalized to tubulin in stripped membranes from the same samples (shown below the VEGF/PEDF blots). Black column: relative levels in ND controls; white column: relative levels in HDD animals. ${ }^{* * * *} P<$ 0.001. Relative levels given in arbitrary units. 

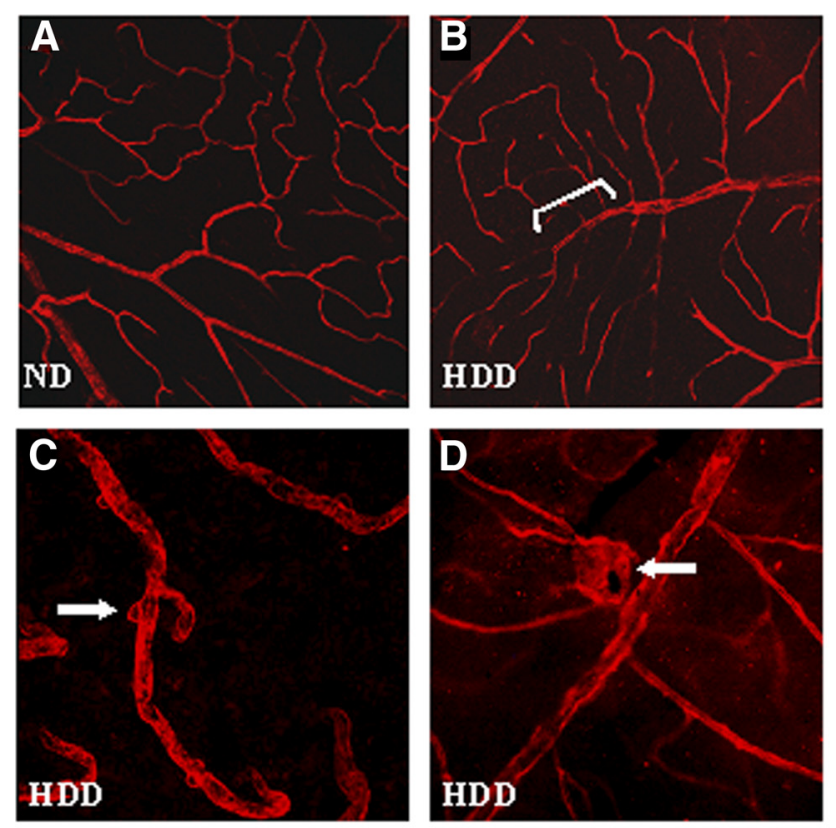
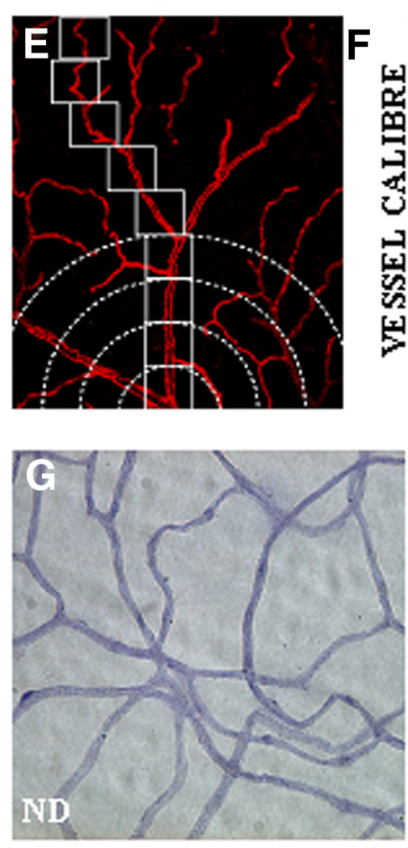

I

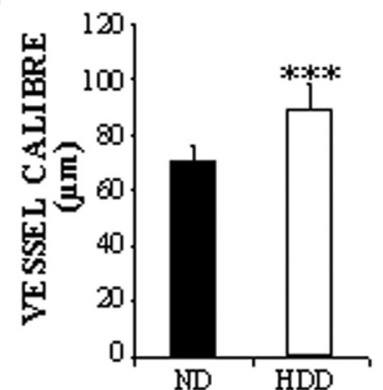

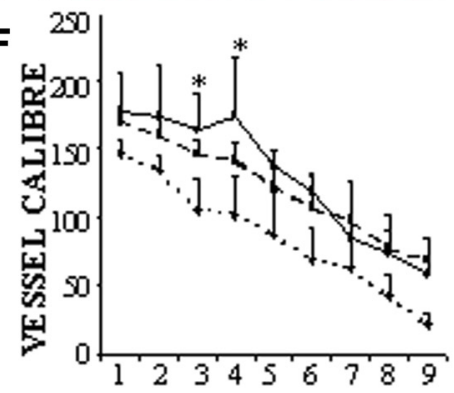

VESSEL E CCENTRICITY

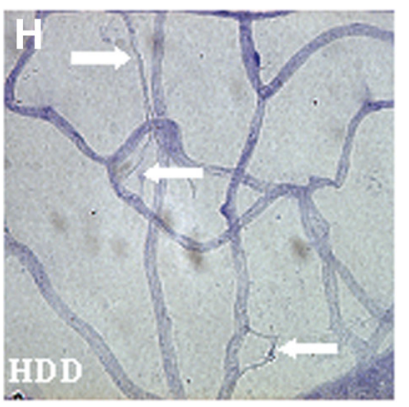

J

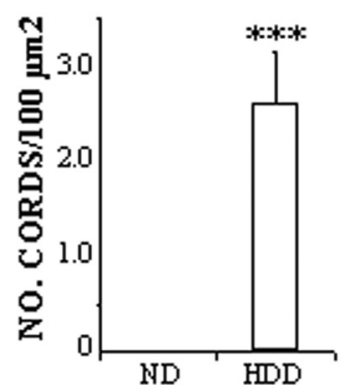

FIGURE 3. Vascular modifications during diabetes in P. obesus. (A-D) Retinas stained with B. simplicifolia isolectin. Although the vessel aspect in control retinas (ND) showed a regular smoothly branching aspect (A), diabetic retinas (HDD) showed a range of abnormalities, including irregular diameter and constrictions (B, open bracket), neovascular buds (C, arrow), and balloon-like swellings (D, arrow). Taken from a confocal stacked set of images to ensure the bud was a blind pled by tight junctions (Fig. 4E). On the other hand, phalloidin staining of HDD eyecups showed weakened junction, as evidenced by splitting between neighboring cells (Fig. 4F). ND eyecups also displayed strict localization of the tight junction marker protein kinase $\mathrm{C}$ (PKC) $\zeta$ to cell borders (Fig. 4G), whereas HDD eyecups showed generalized staining across the cell indicative of delocalization (Fig. $4 \mathrm{H}$ ); the same was true for another tight junction marker, occludin (data not shown). Additional examples of pericyte loss in diabetic retinas are shown in Supplementary Fig. S1, http://www.iovs.org/lookup/ suppl/doi:10.1167/iovs.11-8423/-/DCSupplemental. Pericyte and RPE barrier immunostaining were not performed for HDnD retinas.

\section{General Structural Modifications in P. obesus}

The general retinal aspect of the three groups showed clear differences. ND retinas exhibited regular layers with a thin inner limiting basement membrane (Figs. 5A, 5B), whereas sections of HDD retina exhibited a wider nerve fiber layer with a membranous aspect (Fig. 5C) and displayed thin irregular nuclear layers (Fig. 5D). This was also observed in HDnD retinas (data not shown). Quantitative measures showed that the widths of the outer segment (OS) layer and that of the outer nuclear layer (ONL), inner nuclear layer (INL), and inner plexiform layer (IPL) were significantly reduced in HDnD and HDD retinas (by up to $40 \%, 36 \%, 38 \%$, and $22 \%$ respectively) (Fig. 5E). Similar reductions were noted when cell density was counted within the ONL (up to $26 \%$ less), INL (up to $30 \%$ less), and ganglion cell layer (GCL) (up to $44 \%$ less) (Fig. 5F).

In support of these histologic observations, plexiform layers were clearly visualized by synaptophysin immunostaining of synaptic vesicles. Immunolabel of the two synaptic zones was different between ND and HDD groups. In ND retinas, the synaptic layers were regular and linear (Fig. 5G), whereas in HDD tissue, the OPL was irregular and the IPL was markedly thinner (Fig. 5H). However, and in contrast to other proteins, synaptophysin levels were significantly increased in diabetic retinas (Fig. 5I). Synaptophysin immunoreactivity was not analyzed in HDnD retinas.

\section{Retinal Glial Modifications in P. obesus}

Visualization of glial fibrillar acidic protein (GFAP) immunostaining at the vitreal surface of flat-mounted ND retinas showed filamentous staining, particularly marked around blood vessels (Fig. 6A). However, GFAP staining intensity appeared higher in HDnD retinas and much higher in HDD retinas, both along and between blood vessels (Figs. 6B, 6C). Examination of frozen sections from each group showed that GFAP expression was confined to the nerve fiber layer but with more intense staining because of the hypertrophy in HDD (data not shown). Western blot analysis of protein extracts from each group showed a small but significant increase in intensity

ending (C). Using a morphometric approach in which major blood vessels were traced from the center to the periphery and were divided into nine equivalent zones in which repeated measures of vessel width were made (E), a significant increase in the midperiphery of HDD vessels was observed (F, filled circles) ("P $P$ 0.05, ANOVA). HDnD vessels (filled squares) showed diameters intermediate between those of ND (filled diamonds) and HDD tissues, but these were not statistically significant. Trypsin-digested preparations of ND (G) and HDD (H) tissue showed the presence of cord-like acellular strands in the diseased tissue (white arrows, F). Quantitative analysis of vessel caliber in major blood vessels in trypsin digests also showed a significant increase in HDD tissue (I) $\left({ }^{* * *} P<0.001\right)$. Quantification of acellular cords in trypsin digests showed them to be restricted to HDD tissue $\left({ }^{* * * *} P<\right.$ 0.001). Scale bars: $100 \mu \mathrm{m}(\mathbf{A}, \mathbf{B}, \mathbf{E}, \mathbf{G}, \mathbf{H}) ; 25 \mu \mathrm{m}(\mathbf{C}, \mathbf{D})$. 
ND
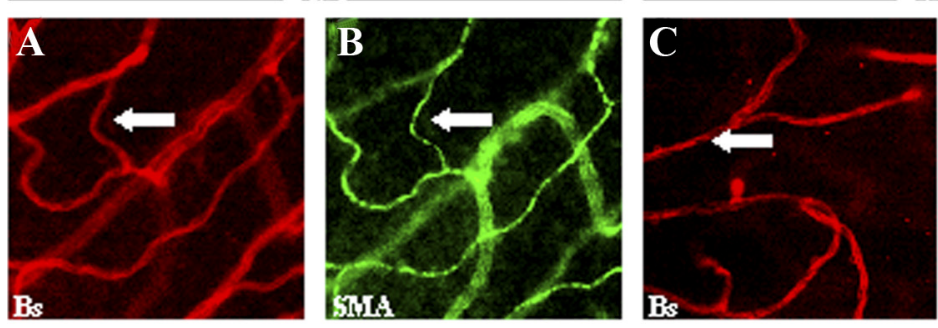

HDD
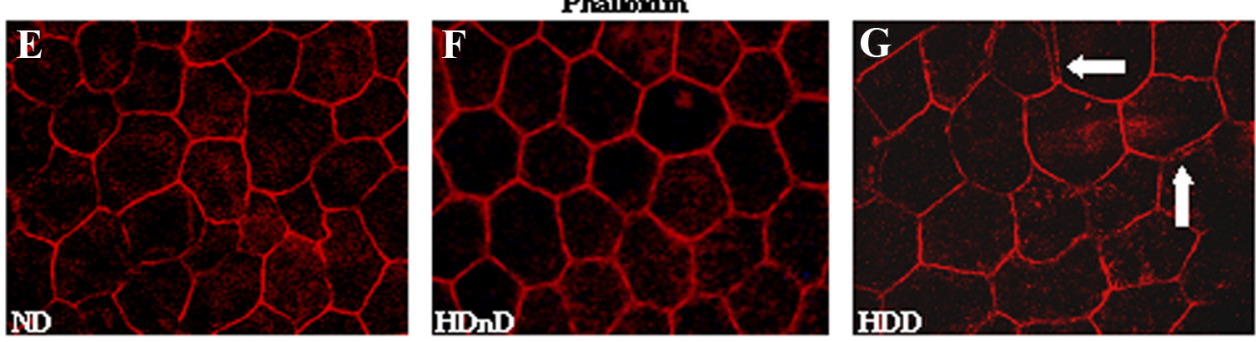

PKC.
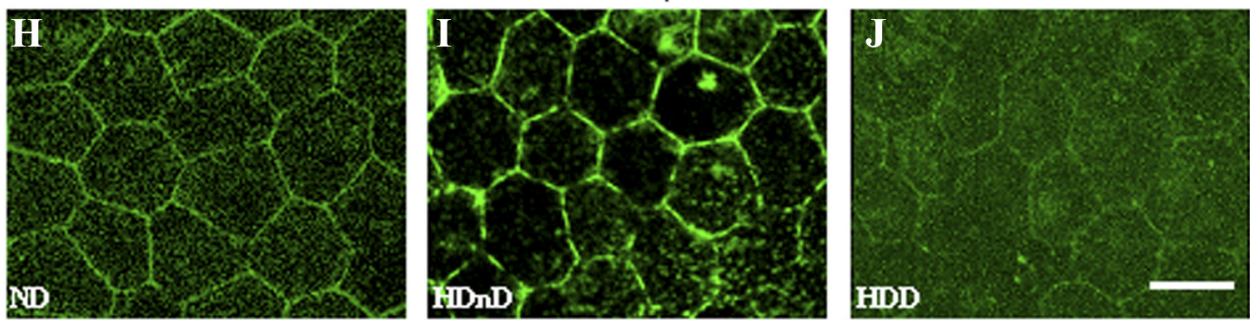

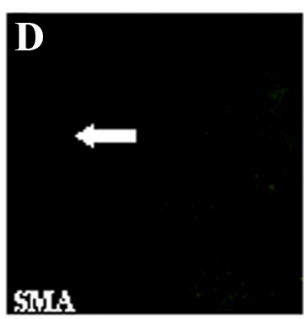

Figure 4. Vascular and blood-retinal barrier modifications during diabetes in $P$. obesus. ND retinas labeled with B. simplicifolia lectin (Bs, red) to outline blood vessels (A) and antismooth muscle actin antibody (SMA, green) to stain pericytes (B) demonstrate the dense pericyte coverage (examples shown by arrows). On the contrary, HDD retinas labeled under identical conditions showed complete absence of pericytes (C, D). RPE monolayer in flat-mounted posterior eyecups (E-J). Staining with fluorescently tagged phalloidin to decorate F-actin was confined to cell borders in ND (E) and HDnD (F) eyes, but in HDD eyes there were signs of cell splitting and separation (arrows, G). $\mathrm{PKC}_{\zeta}$, a major component of tight junctions, was restricted to cell margins in ND $(\mathbf{H})$ and HDnD (I) eyes but was diffusely spread across RPE in HDD eyes (J). All images were taken in the same focal plane, at the level of the nuclei (E-H). Scale bar, $25 \mu \mathrm{m}$. in the HDnD group compared with the ND group and in creases of approximately twofold in HDD compared with ND (Fig. 6D).

In stark contrast to GFAP immunoreactivity, staining for glutamine synthetase (GS) showed an inverse pattern. In ND retinas, labeling was intense across the tissue, outlining the cell bodies in the three cellular layers and filling the plexiform layers (Fig. 6E). HDnD retinas were similar but appeared less intense (Fig. 6F), whereas staining was greatly reduced in sections of HDD retina, particularly in the outer half of the tissue, with radial staining seen in individual Müller glia (Fig. 6G). Again, these qualitative differences were confirmed by Western blot analysis and were seen to be highly significantly different between ND and HDD samples (Fig. 6H). Glutamateaspartate transporter (GLAST) immunoreactivity was also intense in ND retinas, extending from the Müller glial apical microvilli through the nerve fiber layer (Fig. 6I). HDnD retinas displayed similar patterns, although there appeared to be less staining in the INL (Fig. 6J), whereas intensity was much reduced in HDD retinas (Fig. 6K). Western blot analysis showed the difference was statistically significant between ND and HDD retinas (Fig. 6L).

\section{Retinal Neuronal Modifications in Diabetic $P$. obesus}

Retinal ganglion cells (RGCs) were visualized by staining against the $200-\mathrm{kDa}$ subunit of neurofilament, in both retinal wholemounts and frozen sections. As viewed in retinal wholemounts, axonal morphology differed between control and diabetic groups. Axons were smooth and organized into smooth bundles in ND tissue (Fig. 7A) but exhibited numerous varicosities and were often seen as individual fibers in HDD tissue (Fig. 7B). Frozen sections of retinas from ND and HDD animals showed a fairly similar pattern, with strong immunostaining along the nerve fiber layer visible as discrete axon bundles in ND (Fig. 7C) but more diffuse in HDD (Fig. 7D). HDnD RGCs resembled those seen in ND retinas (data not shown). Bipolar cells were stained with antibodies against $\mathrm{PKC} \alpha$ and $\mathrm{PKC}_{\zeta}$ (both restricted to this cell type within the neural retina). In ND tissue, PKC $\alpha$ immunoreactivity was present in cell bodies, axons, and synapses of this population (Fig. 7E). The diabetic state led to a marked reduction in staining intensity so that only background staining was seen in HDD retinas (Fig. 7F). Quantification of PKC $\alpha$ by quantitative Western blot analysis confirmed a significant reduction in HDD retinas (Fig. 7G). Very similar observations were made for $\mathrm{PKC}_{\zeta}$, with immunostaining visible throughout the bipolar cells in ND (Fig. $7 \mathrm{H})$ and HDnD (albeit at reduced intensity) retinas (Fig. 7I) but was reduced to faint synaptic staining in HDD tissue (Fig. 7J). These qualitative results were confirmed by quantitative Western blot analysis, with HDnD samples showing significant reductions and HDD tissue showing highly significant reductions (Fig. $7 \mathrm{~K})$. Horizontal cell staining with parvalbumin antibody was not visibly different between the groups (Figs. 7L, 7M).

\section{Retinal Photoreceptor Modifications in Diabetic P. obesus}

There were notable differences in the responses of the two photoreceptor populations (rods and cones) to the diabeteslike state. Expression of rhodopsin did not differ in intensity or distribution between the three groups (Figs. 8A-C). However, cone mid-wavelength opsin (MOp) staining was detectably reduced in HDD compared with ND and HDD retinas (Figs. 8D-F). This was also the case for cone short-wavelength opsin (SOp) (Figs. 8G, 8H). These qualitative observations were all confirmed by Western blot analysis. Rhodopsin immunostaining was equal between the groups (Fig. 8I), whereas MOp and SOp were reduced to approximately $50 \%$ the levels in HDD 

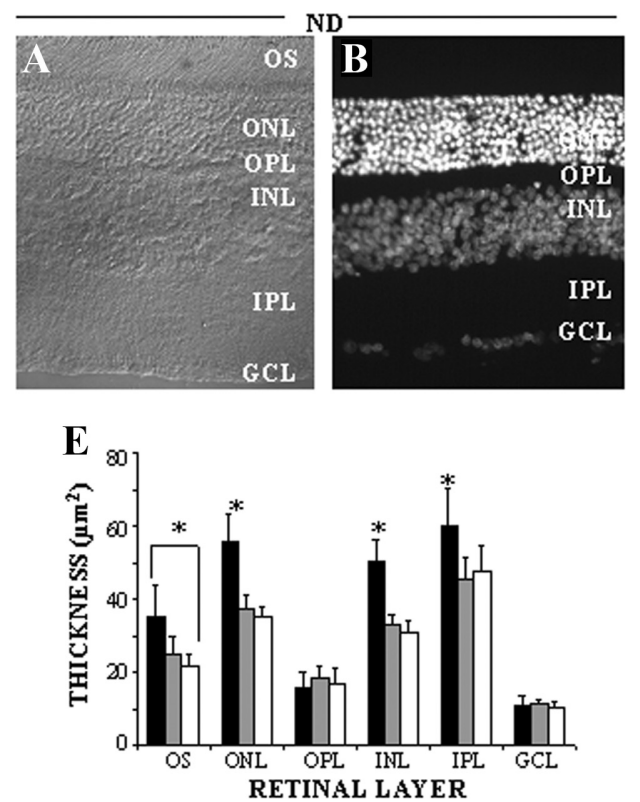
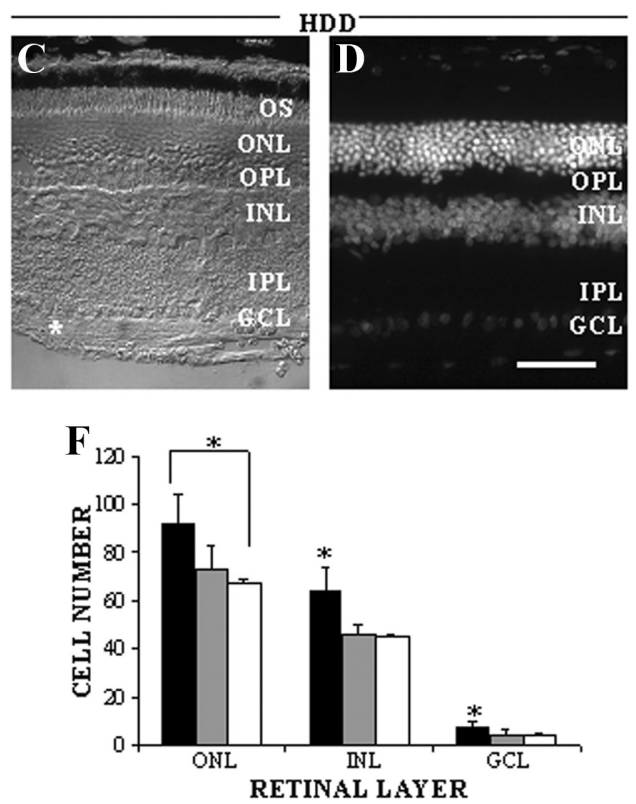
layer thicknesses (OS, ONL, INL, IPL) and cell numbers (ONL, INL, GCL) in HDD compared with ND animals $(P<0.05$; ANOVA $)$. HDnD measures were also significantly different from ND values for ONL, INL, and IPL for layer width and for INL and GCL for cell density ( $P<0.05$; ANOVA). Synaptophysin (SVP38) immunostaining was intense in both plexiform layers in ND (G) and HDD P. obesus $(\mathbf{H})$. Western blot analysis and quantification of synaptophysin expression showed it was significantly increased in HDD retinas (I) $\left({ }^{*} P<0.05\right.$, ANOVA). OS, outer segments. Scale bar, $50 \mu \mathrm{m}(\mathbf{A}-\mathbf{D}, \mathbf{G}, \mathbf{H})$

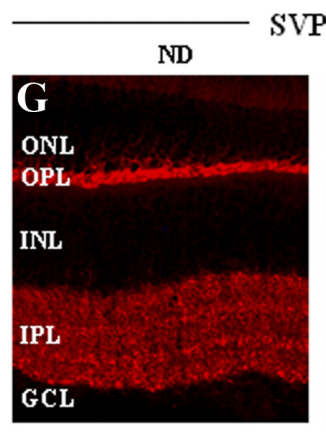

HDD

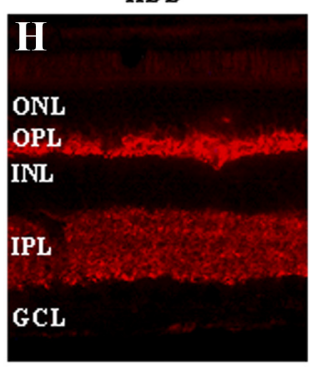

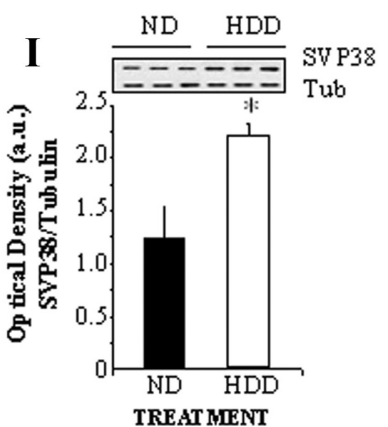

retinas (Figs. 8J, 8K). MOp levels in $\mathrm{HDnD}$ retinas were similar to ND values (Fig. 8J). We examined several additional markers of specific rod or cone types, or both, under the two experimental conditions. Expression of the rod and cone OS structural protein peripherin/rds, visible uniquely in OS, was similar between ND and HDD retinas (Supplementary Figs. S2A, S2B, http://www.iovs.org/lookup/suppl/doi:10.1167/iovs.118423/-/DCSupplemental); arrestin staining was observed throughout the photoreceptor layer in both retinas (Supplementary Figs. S2C, S2D, http://www.iovs.org/lookup/suppl/ doi:10.1167/iovs.11-8423/-/DCSupplemental); and recoverin was also approximately equal under both conditions (Supplementary Figs. S2E, S2F, http://www.iovs.org/lookup/suppl/ doi:10.1167/iovs.11-8423/-/DCSupplemental). Both rod and cone transducin appeared equal between the normal and diseased conditions (Supplementary Figs. S2G-J, http:// www.iovs.org/lookup/suppl/doi:10.1167/iovs.11-8423/-/ DCSupplemental).

\section{Discussion}

Diet-induced metabolic stress syndrome in the sand rat $P$. obesus leads to a number of pathologic alterations in their eyes. These modifications include a range of abnormal features associated with control of the vasculature (within the vessels themselves: vasodilation, increased tortuosity, vascular sprouts, occluded vessels and small swellings; increased total protein and radically opposing concentrations of VEGF and PEDF within the vitreous, splitting of the RPE monolayer, and delocalization of tight junction proteins forming the blood-retina barrier). There was an extensive series of remodeling events and phenotypic changes in retinal glia and neurons. To the extent to which data are available for human DR, the two conditions are remarkably similar.

There is extensive literature on the use of P. obesus as an experimental model for investigating the development and effects of metabolic syndrome leading to obesity, dyslipidemia, hypertension, and type 2 diabetes. ${ }^{18}$ Studies indicate that overly rich diets may lead to the development of hyperinsulinemia through ineffective extraction of excess insulin by liver receptors. Hyperinsulinemia, in turn, causes a reversible reduction in receptor kinase activity, leading to insulin resistance. ${ }^{19}$ Furthermore, marked insulin depletion is observed in diabetic islets, probably because of a hyperglycemia-driven increase in secretory demand that cannot be compensated. ${ }^{20}$ The similarities among metabolic, physiological, and endocrine changes in this species compared with those in human type 2 diabetes make it a highly relevant animal model with which to understand the pathogenesis of this condition. ${ }^{12,13,18}$ In the present study, $>50 \%$ of the animals maintained on hypercaloric diets spontaneously developed characteristics of diabetes (obesity and elevated blood sugar levels), and all exhibited DR. The intermediate group was not examined for every parameter, but it displayed a variable phenotype ranging from no difference to large differences compared with the plant-fed group. This group experienced significant weight gains without elevated blood glucose levels and also displayed moderate retinal symptoms, as indicated by reduced width and cell numbers, in- 

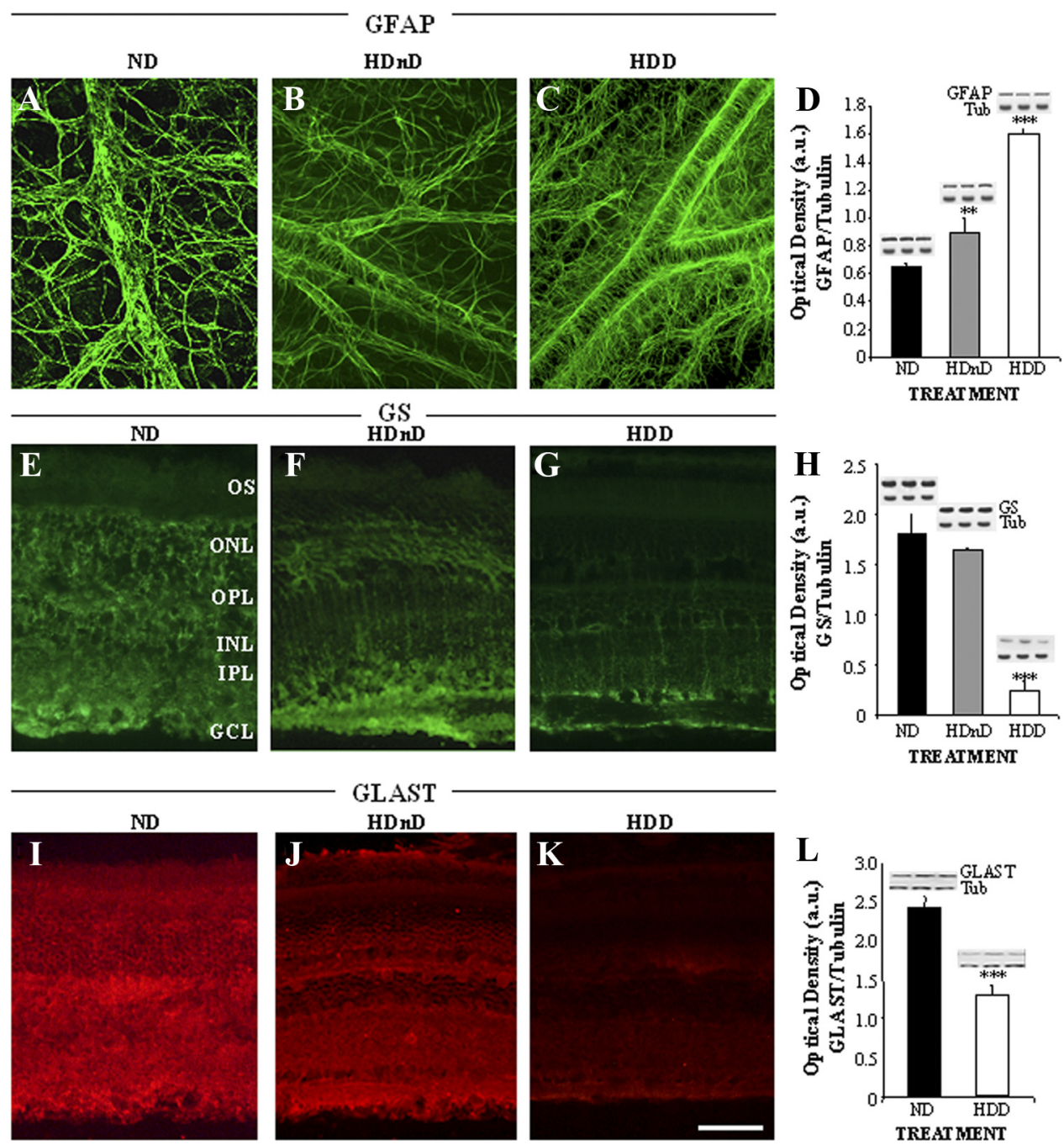

FiguRE 6. Glial alterations in retinas of $P$. obesus. Immunohistochemical and Western blot analyses of glial fibrillar acidic protein (GFAP) (A-D), glutamine synthetase (GS) (E-H), and GLAST (I-L). GFAP-containing astrocytes were distributed across the vitreal face of flat-mounted ND retinas, especially concentrated along major blood vessels (A). Similar views of $\mathrm{HDnD}$ retinas showed intense staining around blood vessels and higher amounts between vessels (B). Observation of the vitreal face of HDD retinas showed very high numbers of GFAP-immunopositive astrocytes across the surface (C). Increased GFAP expression in HDnD and HDD animals was confirmed by densitometric scanning of Western blots, expressed in arbitrary units (a.u.) normalized to tubulin ( $n=3$ per retina, shown above each corresponding column) (D). Compared with ND samples (black columns), there were large increases in HDnD (gray columns, ${ }^{* * *} P<0.01$, ANOVA) and HDD (white columns, ${ }^{* * *} P<0.001$, ANOVA). GS immunoreactivity was robust across the entire retina in ND (E) and HDnD (F) animals but was greatly reduced in HDD animals (G). Western blot analysis and densitometric scans confirmed the decreased expression for GS (H). Triplicate Western blots for GS and tubulin are shown above each column. GLAST immunostaining was also strong in ND (I) and HDnD (J) retinas and decreased in HDD retinas (K). As for GS, quantitative Western blots confirmed the decrease (L), and triplicate Western blots for GLAST and tubulin are shown above the columns ( ${ }^{* * * *} P<0.001$, ANOVA). MV, Müller glial microvilli; OS, outer segments; Tub, tubulin. Scale bars: $20 \mu \mathrm{m}$ (A-C); $50 \mu \mathrm{m}$ (E-G, I-K).

creased expression of GFAP, and decreased expression of $\mathrm{PKC}_{\zeta}$. However, most of these changes were smaller than those seen in HDD animals and were not significantly different for GS or mid- or long-wavelength cone opsin. This intermediate group may represent latent animals who responded to dietary imbalances with delayed-onset or refractory diabetes compared with the HDD group. Similar percentages of diabetes-susceptible (40\%) and diabetes-resistant animals have been reported in previous studies on Psammomys, ${ }^{21}$ and analysis of the two populations has permitted identification of a major susceptibility gene. ${ }^{22}$

A major question concerns the potential advantages and disadvantages of this new animal model for DR. According to the Animal Models of Diabetic Complications Consortium (AMDCC), useful models should exhibit capillary and neuronal loss and capillary obliteration (features of early-stage nonproliferative diabetic retinopathy [NPDR]), retinal edema, and preretinal neovascularization (associated with PDR). Many experimental models have been developed and characterized for their pertinence to the human disease, but most replicate only aspects of NPDR. Some do progress to PDR, which is responsible for severe vision loss but at advanced age (e.g., spontaneously diabetic Torii rats $>50$ weeks of age). ${ }^{23}$ Diet-induced DR in Psammomys satisfies most of the criteria cited by the AMDCC. It is typified by a range of vascular abnormalities and widespread neuronal loss, and the presence of acellular capil- 
FIGURE 7. Neuronal modifications in $P$. obesus retina. (A) Flat-mounted ND retina immunostained with neurofilament (NF200 kDa) antibody showing smooth axon bundles (arrow). (B) On the contrary, axons in HDD retinas revealed moderate defasciculation and numerous varicosities (arrow). A similar result was seen in frozen crosssections, with large neurofilament-immunopositive bundles seen along the nerve fiber layer in ND samples (C) but thinner variable staining in HDD animals (D). In ND retinas, PKC $\alpha$ antibody showed clear staining in cell bodies within the inner nuclear layer (INL), as well as their axons and synaptic endings in the inner plexiform layer (IPL), corresponding to rod and cone ON bipolar cells (E). HDD retinas showed almost complete disappearance of PKC $\alpha$ staining $(\mathbf{F})$, which was confirmed by quantitative Western blot analysis as described earlier (triplicate lanes for ND and HDD retinas, top) (G). $\mathrm{PKC}_{\zeta}$ immunostaining revealed a pattern similar to that of PKC $\alpha$ in ND retinas (H) and a less intense signal in HDnD retinas (I), whereas in HDD retinas residual staining was visible in the synapses $(\boldsymbol{J})$. Reduced staining was again confirmed by Western blot analysis (K). Quantitative densitometric measurement of band densities compared to tubulin (Tub) confirmed the decreases in HDnD $\left({ }^{* *} P<0.01\right.$, ANOVA $)$ and HDD $\left({ }^{* * * *} P<\right.$ 0.001, ANOVA) samples. Triplicate blots of $\mathrm{PKC}_{\zeta}$ and tubulin are shown above each corresponding column: ND (black), HDnD (gray), HDD (white). Histologic sections of $P$. obesus retina immunostained with parvalbumin antibody were very similar in ND (L) and HDD (M) animals. OS, outer segments. Scale bars: $20 \mu \mathrm{m}$ (A, B); $50 \mu \mathrm{m}(\mathbf{C}-\mathbf{F}, \mathbf{H}-\mathbf{J}) ; 80 \mu \mathrm{m}(\mathbf{L}, \mathbf{M})$.

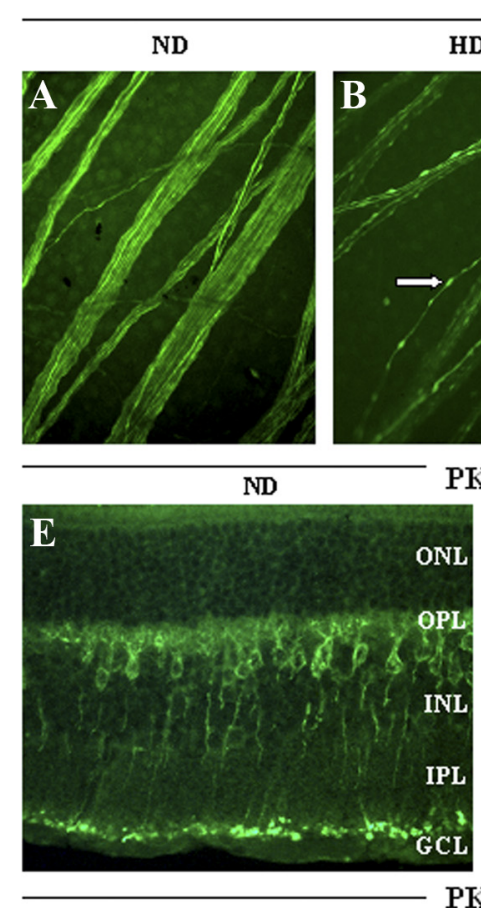

NF

HDD
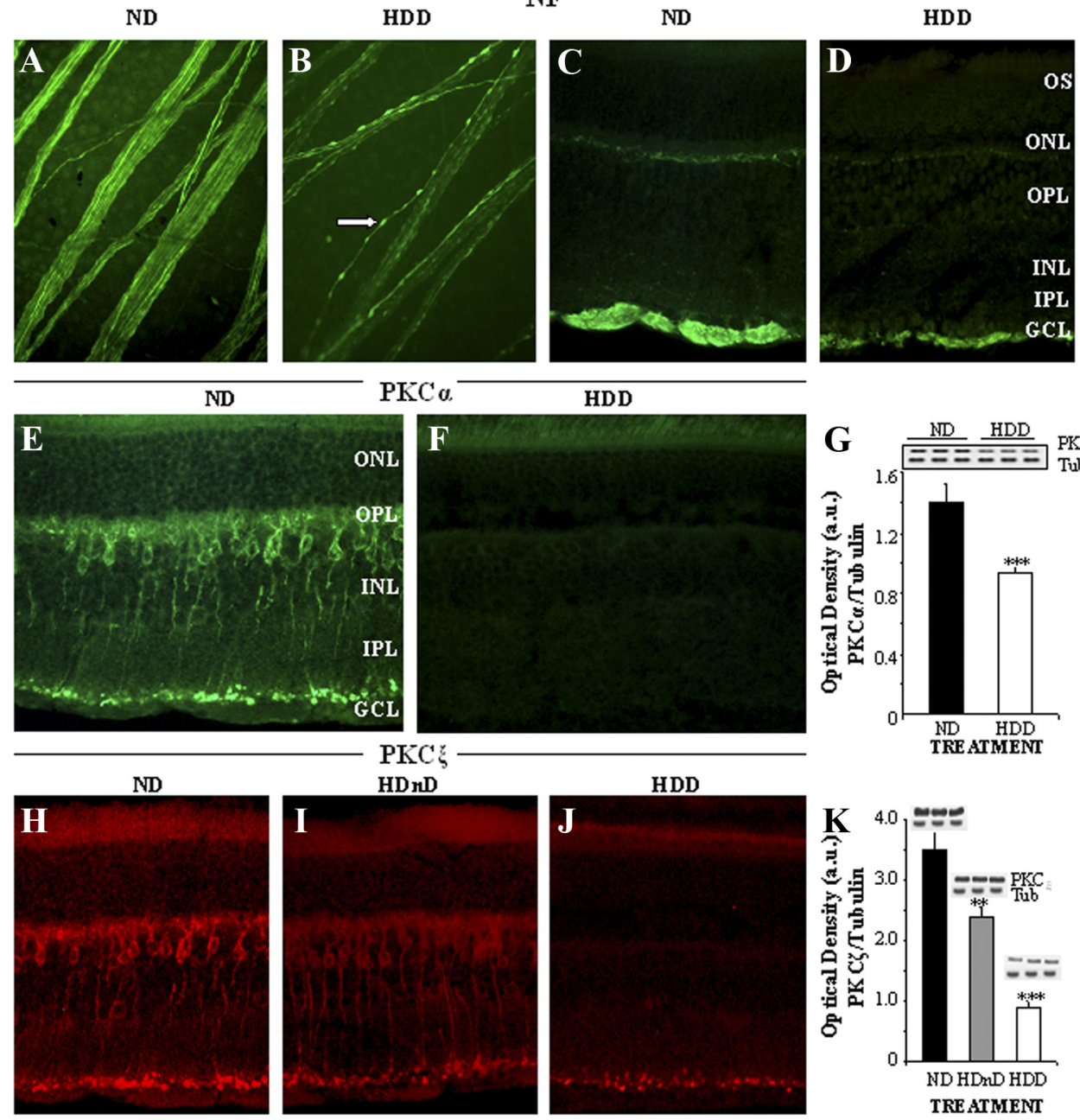

ND

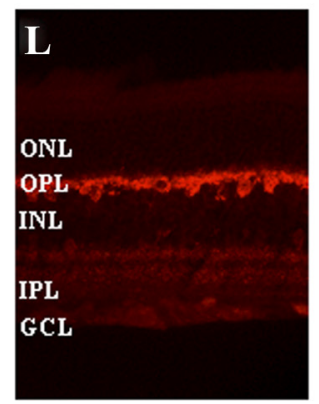

HDD

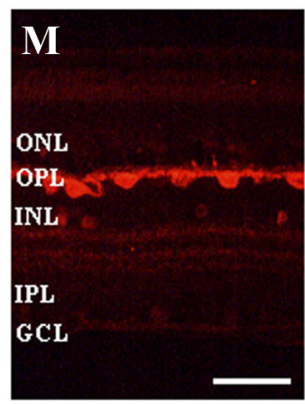

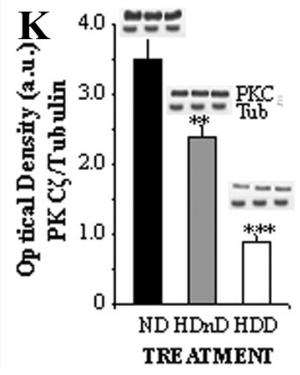

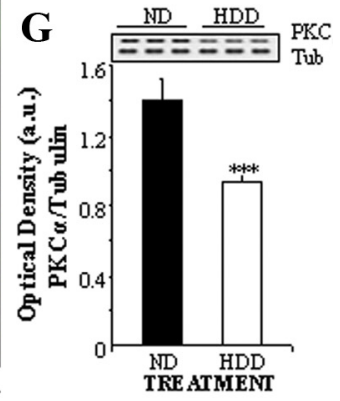

TRE ATMENT laries indicates the formation of obliterated nonfunctional microvessels, as seen in humans. ${ }^{16}$ Psammomys showed dramatic pericyte loss in diabetic retinas, with almost complete disappearance from vessel surfaces. Pericyte dropout represents the earliest detectable vascular change in animal models of DR and is a hallmark feature of human DR. ${ }^{24}$ In the present study, we did not specifically examine preretinal hemorrhage and neovascularization, but two observations argue that it develops in our model: increased vitreal protein concentrations indicate leakage from new blood vessels, ${ }^{25}$ and the huge imbalance in proangiogenic and antiangiogenic factors measured in the vitreous of diabetic animals is strongly correlated with the development of PDR in humans. ${ }^{26-29}$ Indeed, increased VEGF/PEDF ratios were directly correlated with the degree and progression of retinal neovascularization in another pathologic mouse model. ${ }^{30}$ We did not investigate retinal edema in the present study because eyes were dissected and fixed before examination. To the best of our knowledge, only one animal model has so far been described that exhibits PDR: the Akimba mouse, a genetic model of type 1 DR (double transgenic Ins2 $2^{\text {akita }} /$ VEGF mice). ${ }^{31}$ It should be emphasized that unlike the Akimba mouse, the current model is generated solely by mild dietary overload, with no genetic overexpression of VEGF, and constitutes a faithful model of metabolic syndrome/type 2 diabetes. Furthermore the observed changes occurred within 7 months of hypercaloric diet, considerably faster than the passage to PDR in other animal models. ${ }^{23}$

We especially focused on nonvascular aspects of DR because these often precede blood vessel remodeling and may be causal events in functional decline. Such alterations are difficult 

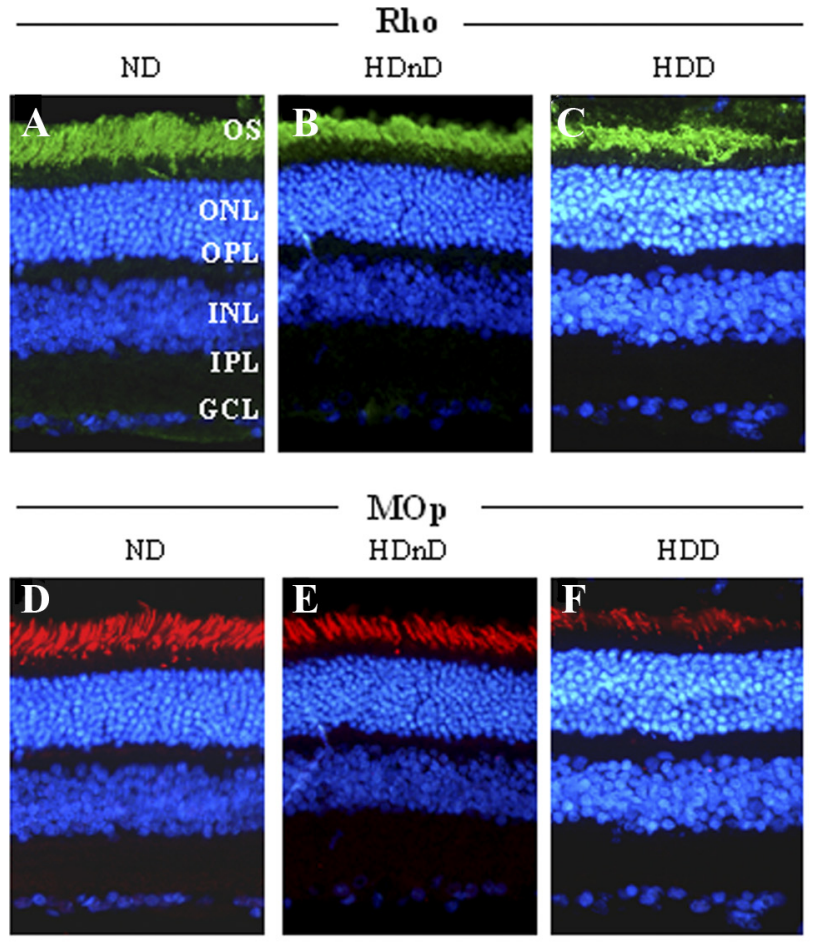

$$
\begin{aligned}
& \text { MOp } \\
& \text { HDnD }
\end{aligned}
$$
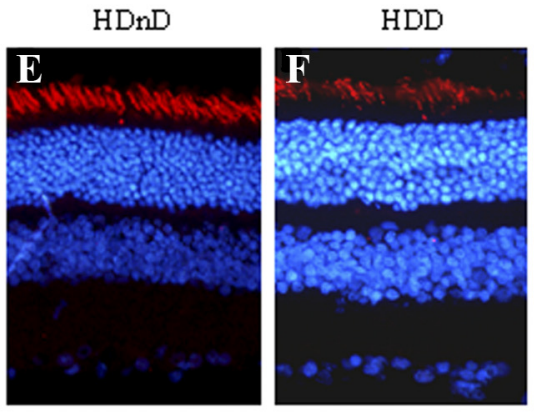

$\mathbf{J}$

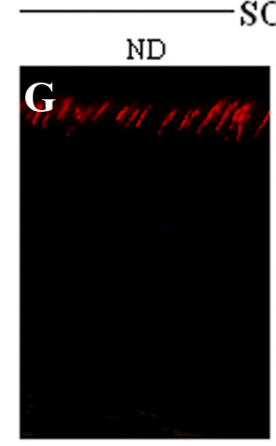

$\mathrm{SOp}$

\begin{abstract}
HDD
\end{abstract}

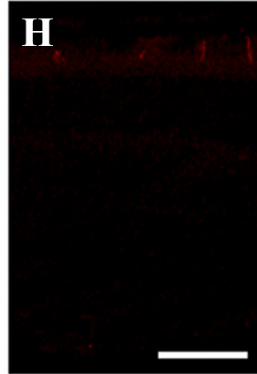

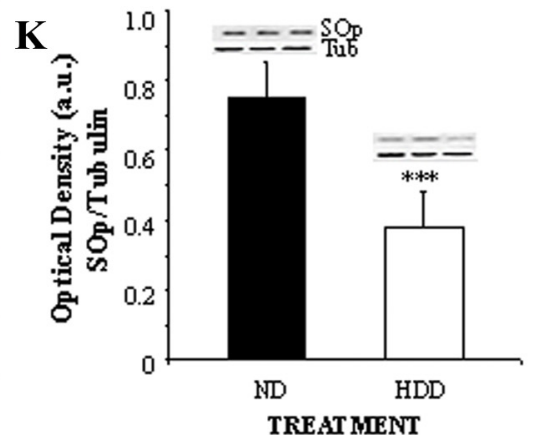
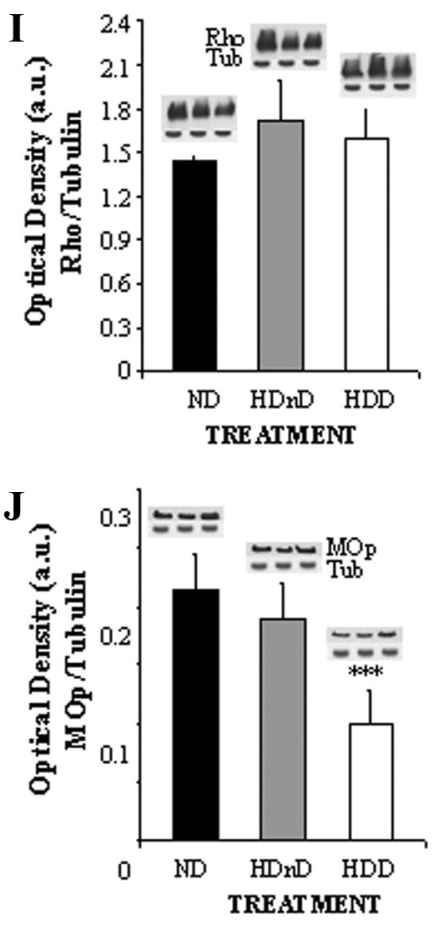

Figure 8. Rod and cone photoreceptor opsins in $P$. obesus retina. Rhodopsin (Rho) immunolabeling showed strong expression in rod outer segments (OS, green) in ND (A), HDnD (B), and HDD (C) animals. Staining of cone mid wavelength opsin (MOp) was localized to numerous cone outer segments (OS, red) in ND (D) and HDnD (E) animals, whereas there were many less immunolabeled cells in HDD tissue (F). This was also the case for cone short wavelength (SOp) immunostaining in OS of ND (G) and HDD animals (H). Western blot analysis and quantification of Rho, MOp, and SOp expression. (I) Rho and tubulin (Tub) immunoreactivity showed no difference in intensity between samples. Triplicate samples are shown above corresponding columns: ND (black), HDnD (gray), HDD (white). (J) MOp immunoreactivity showed a roughly $50 \%$ decrease in HDD retinas when normalized to Tub $(* * * P<$ 0.001, ANOVA). (K) Similarly, SOp immunoreactivity was also reduced by $50 \%$ in HDD retinas ${ }^{(* * * *} P<0.001$, ANOVA). Scale bar, $80 \mu \mathrm{m}$. to study in a methodical manner in humans. We paid great attention to cone photoreceptor changes because deficits in color vision and contrast sensitivity are among the earliest indications of DR in humans, occurring long before clinically detectable vascular defects. ${ }^{5-7}$ We saw no significant changes in rhodopsin levels between control and diabetic animals. In contrast, both short-wavelength and mid-/long-wavelength cones were strongly affected, with significant reductions in both populations. Importantly, cone opsin expression was not altered in the obese nondiabetic group, indicating it is causally linked to the hyperglycemic state. Perturbations in the blueyellow axis have been particularly implicated in $\mathrm{DR},{ }^{7}$ and blue cone dropout has been observed in postmortem human DR. ${ }^{32}$ Recent studies ${ }^{33}$ in a zebrafish model of type I NPDR revealed that cones were highly sensitive to hyperglycemia, independent of vascular changes. Differential susceptibility of rods and cones in hyperglycemic conditions might be attributed to glucose use; cone physiology is known to have a higher dependence on correct glucose balance. ${ }^{34}$ With respect to permitting detailed examination of the pathogenesis involved in cone degeneration, $P$. obesus offers the major advantage of a high cone percentage $(\sim 40 \%)^{35}$ compared with conventional laboratory rats and mice with $<3 \%$ cones. ${ }^{36,37}$ Although there are clear differences in diurnal rodent and human retina (e.g., rodents do not have a macula and lack a distinct long-wavelength cone), their rod/cone ratio and axonal density in the optic nerve resemble human central retina (Matter JM, personal communication, 2011). Their retinas have a structural organization that facilitates quantitative measurement of rod and cone density and survival, ${ }^{16,38}$ and visual function can be readily followed by standard electroretinography. ${ }^{38}$ In the latter, diurnal rodents show robust photopic responses to highfrequency flicker electroretinography, similar to that of humans but not seen in mice and rats. ${ }^{38}$

It is likely that glial malfunction is a major factor in DR. Retinal Müller glial cells are clearly implicated in its pathogenesis, ${ }^{39}$ perturbation of their function impinges directly on neuronal survival, ${ }^{40}$ and they are implicated in insulin signaling and glucose metabolism in the retina. ${ }^{40}$ In the present study, retinal glia displayed marked downregulation of two key proteins involved in glutamate detoxification, GLAST and glutamine synthetase (GS). Although GS showed no differences between normal and diabetic postmortem human retinas, ${ }^{41}$ numerous studies in rodent models show clear reductions of both. ${ }^{42,43}$ Furthermore, elevated vitreal glutamate concentrations are found in both animal ${ }^{44}$ and human ${ }^{27} \mathrm{DR}$, indicating a failure of glutamate metabolism. The large upregulation of the glial stress marker GFAP is commonly seen in different models 
of retinal degeneration. ${ }^{45}$ Some reports ${ }^{41}$ show increased expression of GFAP in human DR, and all describe animal models of DR that demonstrate an upregulation of GFAP. ${ }^{31,40,46,47}$

We observed neuronal loss in all layers, as occurs during DR. ${ }^{46,48}$ However, because these decreases were primarily also seen in obese nondiabetic animals, they may not be linked to elevated glucose levels but to some other aspect of metabolic syndrome. Ganglion cells are the best-studied neuronal type in diabetes, ${ }^{48,49}$ and several reports show cell loss and axonal damage in both human ${ }^{50}$ and animal ${ }^{46,49}$ models of DR. The ganglion cell axonal swellings seen in the present study have been observed in human $\mathrm{DR},{ }^{50}$ and the Ins $2^{\text {akita }}$ transgenic mouse model of $\mathrm{DR}^{51}$ and are considered to indicate axonal degeneration. To the best of our knowledge, this is the first report of diabetes-induced decreases in PKC expression in bipolar cells and may be related to perturbed inner retinal function seen in DR, such as alterations in oscillatory potentials. $^{52}$

In conclusion, $P$. obesus represents a potentially valuable novel animal model of human type 2 DR. Not only is disease induction (enriched diet) very similar to a major cause of human type 2 diabetes, but the wide spectrum of retinal modifications is not seen in other laboratory models and arises relatively rapidly. Alterations in cone-mediated color vision constitute one of the earliest characteristics of human DR and may represent a "biomarker" for early diagnosis. The animal presents a major advantage in terms of analyzing the pathogenic mechanisms underlying structural and functional cone degeneration. We are undertaking functional studies of retinal visual responses to diabetes and mapping the progression of retinal changes in respect to the duration of hyperglycemia. The model will furthermore permit testing of potential therapeutic strategies such as insulin treatment, dietary control, and pharmacologic intervention.

\section{Acknowledgments}

The authors thank Patricia Tiazzi (INSERM U872, Paris, France) for helpful discussion, Jorgé Mendoza (Département de Neurobiologie des Rythmes, CNRS UPR 3212, INCI, Strasbourg, France) for assistance with statistical analysis, and Claudine Boissier for expert technical assistance.

\section{References}

1. Wong TY, Klein R, Islam FM, et al. Diabetic retinopathy in a multiethnic cohort in the United States. Am J Opbthalmol. 2006; 141:446-455

2. Garner A. Pathology of diabetic retinopathy. Br Med Bull. 2006; 26:137-142

3. Frank RN. Diabetic retinopathy. $N$ Engl J Med. 2004;350:48-58.

4. Dosso AA, Bonvin ER, Morel Y, Golay A, Assal JP, Leuenberger PM. Risk factors associated with contrast sensitivity loss in diabetic patients. Graefes Arch Clin Exp Ophthalmol. 1996;234:300-305.

5. Gregori B, Papazachariadis O, Farruggia A, Accornero N. A differential color flicker test for detecting acquired color vision impairment in multiple sclerosis and diabetic retinopathy. J Neurol Sci. 2011;300:130-134

6. Roy MS, Gunkel RD, Podgor MJ. Color vision defects in early diabetic retinopathy. Arch Opbthalmol. 1986;104:225-228.

7. Yamamoto S, Kamiyama M, Nitta K, Yamada T, Hayasaka S. Selective reduction of the $\mathrm{S}$ cone electroretinogram in diabetes. $\mathrm{Br} \mathrm{J}$ Ophthalmol. 1996;80:973-975.

8. Rees DA, Alcolado JC. Animal models of diabetes mellitus. Diabet Med. 2005;22:359-370.

9. Armstrong D, Al-Awadi F. Lipid peroxidation and retinopathy in streptozotocin-induced diabetes. Free Radic Biol Med. 1991;11: 433-436.

10. Barber AJ, Antonetti DA, Kern TS, et al. The Ins2Akita mouse as a model of early retinal complications in diabetes. Invest Opbthalmol Vis Sci. 2005;46:2210-2218.
11. Shafrir E, Ziv E. A useful list of spontaneously arising animal models of obesity and diabetes. Am J Physiol Endocrinol Metab. 2009; 296:1450-1452.

12. Schmidt-Nielsen $\mathrm{K}$, Haines HB, Hackel DB. Diabetes mellitus in the sand rat induced by standard laboratory diets. Science. 1963;143: $689-690$.

13. Nesher R, Gross DJ, Donath MY, Cerasi E, Kaiser N. Interaction between genetic and dietary factors determines beta-cell function in Psammomys obesus, an animal model of type 2 diabetes. Diabetes. 1999;48:731-737

14. Larabi Y, Dahmani Y, Gernigon T, Nguyen-Legros J. Tyrosine hydroxylase immunoreactivity in the retina of the diabetic sand rat Psammomys obesus. J Hirnforsch. 1991;32:525-531.

15. Bobu C, Craft CM, Masson-Pevet M, Hicks D. Photoreceptor organization and rhythmic phagocytosis in the nile rat Arvicantbis ansorgei: a novel diurnal rodent model for the study of cone pathophysiology. Invest Ophthalmol Vis Sci. 2006;47:3109-3118.

16. Mizutani M, Kern TS, Lorenzi M. Accelerated death of retinal microvascular cells in human and experimental diabetic retinopathy. J Clin Invest. 1996;97:2883-2890.

17. Hughes WF. Quantitation of ischemic damage in the rat retina. Exp Eye Res. 1991;53:573-582.

18. Walder K, Oakes N, Fahey RP, Cooney G, Zimmet PZ, Collier GR. Profile of dyslipidemia in Psammomys obesus, an animal model of the metabolic syndrome. Endocr Regul. 2002;36:1-8.

19. Kanety H, Moshe S, Shafrir E, Lunenfeld B, Karasik A. Hyperinsulinemia induces a reversible impairment in insulin receptor function leading to diabetes in the sand rat model of non-insulindependent diabetes mellitus. Proc Natl Acad Sci U S A. 1994;91: 1853-1857.

20. Gadot M, Ariav Y, Cerasi E, Kaiser N, Gross DJ. Hyperproinsulinemia in the diabetic Psammomys obesus is a result of increased secretory demand on the beta-cell. Endocrinology. 1995;136: 4218-4223.

21. Marquié G, Duhault J, Jacotot B. Diabetes mellitus in sand rats (Psammomys obesus): metabolic pattern during development of the diabetic syndrome. Diabetes. 1984;33:438-443.

22. Hillel J, Gefel D, Kalman R, et al. Evidence for a major gene affecting the transition from normoglycaemia to hyperglycaemia in Psammomys obesus. Heredity. 2005;95:158-165.

23. Matsuoka M, Ogata N, Minamino K, Higuchi A, Matsumura M. High levels of pigment epithelium-derived factor in the retina of a rat model of type 2 diabetes. Exp Eye Res. 2006;82:172-178.

24. Hammes HP, Lin J, Renner O, et al. Pericytes and the pathogenesis of diabetic retinopathy. Diabetes. 2002;5:3107-3112.

25. Koyama R, Nakanishi T, Ikeda T, Shimizu A. Catalogue of soluble proteins in human vitreous humor by one-dimensional sodium dodecyl sulfate-polyacrylamide gel electrophoresis and electrospray ionization mass spectrometry including seven angiogenesisregulating factors. J Chromatogr B Analyt Technol Biomed Life Sci. 2003;792:5-21.

26. Aiello LP, Avery RL, Arrigg PG, et al. Vascular endothelial growth factor in ocular fluid of patients with diabetic retinopathy and other retinal disorders. N Engl J Med. 1994;331:1480-1487.

27. Ambati J, Chalam KV, Chawla DK, et al. Elevated gamma-aminobutyric acid, glutamate, and vascular endothelial growth factor levels in the vitreous of patients with proliferative diabetic retinopathy. Arch Ophthalmol. 1997;115:1161-1166.

28. Nam DH, Oh J, Roh JH, Huh K. Different expression of vascular endothelial growth factor and pigment epithelium-derived factor between diabetic and non-diabetic epiretinal membranes. $O p h$ thalmologica. 2009:223;188-191.

29. Ogata N, Nishikawa M, Nishimura T, Mitsuma Y, Matsumura M. Unbalanced vitreous levels of pigment epithelium-derived factor and vascular endothelial growth factor in diabetic retinopathy. Am J Opbthalmol. 2002;134:348-353.

30. Gao G, Li Y, Zhang D, Gee S, Crosson C, Ma J. Unbalanced expression of VEGF and PEDF in ischemia-induced retinal neovascularization. FEBS Lett. 2001;489:270-276.

31. Rakoczy EP, Ali Rahman IS, Binz N, et al. Characterisation of a mouse model of hyperglycemia and retinal neovascularisation. Am J Patbol. 2010;177:2659-2670. 
32. Cho NC, Poulsen GL, Ver Hoeve JN, Nork TM. Selective loss of S-cones in diabetic retinopathy. Arch Opbthalmol. 2000;118: 1393-1400.

33. Alvarez Y, Chen K, Reynolds AL, Waghorne N, O'Connor JJ, Kennedy BN. Predominant cone photoreceptor dysfunction in a hy perglycaemic model of non-proliferative diabetic retinopathy. Dis Model Mech. 2010;3:236-245.

34. Kurtenbach A, Mayser HM, Jägle H, Fritsche A, Zrenner E. Hyperoxia, hyperglycemia, and photoreceptor sensitivity in normal and diabetic subjects. Vis Neurosci. 2006;23:651-661.

35. Saidi T, Mbarek S, Ben Chaouacha-Chekir R, Hicks D. Diurna rodents as animal models of human central vision: characterization of the retina of the sand rat Psammomys obesus. Graefe's Arch Clin Exp Opbthalmol. 2011;249:1029-1037.

36. Jeon CJ, Strettoi E, Masland RH. The major cell populations of the mouse retina. J Neurosci. 1998;18:8936-8946.

37. Szel A, Rohlich P. Two cone types of rat retina detected by anti-visual pigment antibodies. Exp Eye Res. 1992;55:47-52.

38. Boudard DL, Tanimoto N, Huber G, Beck SC, Seeliger MW, Hicks D. Cone loss is delayed relative to rod loss during induced retinal degeneration in the diurnal cone-rich rodent Arvicanthis ansorgei. Neuroscience. 2010;169:1815-1830.

39. Zong H, Ward M, Madden A, et al. Hyperglycaemia-induced proinflammatory responses by retinal Müller glia are regulated by the receptor for advanced glycation end-products (RAGE). Diabetologia. 2010;53:2656-2666.

40. Bringmann A, Pannicke T, Grosche J, et al. Müller cells in the healthy and diseased retina. Prog Retin Eye Res. 2006;25:397-424.

41. Mizutani M, Gerhardinger C, Lorenzi M. Müller cell changes in human diabetic retinopathy. Diabetes. 1998;47:445-449.

42. Li Q, Puro DG. Diabetes-induced dysfunction of the glutamate transporter in retinal Müller cells. Invest Opbthalmol Vis Sci. 2002;43:3109-3116.
43. Yu XH, Zhang H, Wang YH, Liu LJ, Teng Y, Liu P. Time-dependent reduction of glutamine synthetase in retina of diabetic rats. Exp Eye Res. 2009;89:967-971.

44. Lieth E, Barber AJ, Xu B, et al. Glial reactivity and impaired glutamate metabolism in short-term experimental diabetic retinopathy: Penn State Retina Research Group. Diabetes. 1998;47:815-820.

45. Eisenfeld AJ, Bunt-Milam AH, Sarthy PV. Müller cell expression of glial fibrillary acidic protein after genetic and experimental photoreceptor degeneration in the rat retina. Invest Ophthalmol Vis Sci. 1984;25:1321-1328.

46. Barber AJ, Lieth E, Khin SA, Antonetti DA, Buchanan AG, Gardner TW. Neural apoptosis in the retina during experimental and human diabetes: early onset and effect of insulin. J Clin Invest. 1998; 102:783-791.

47. Rungger-Brändle E, Dosso AA, Leuenberger PM. Glial reactivity, an early feature of diabetic retinopathy. Invest Ophthalmol Vis Sci. 2000;41:1971-1980.

48. Fletcher EL, Phipps JA, Ward MM, Puthussery T, Wilkinson-Berka JL. Neuronal and glial cell abnormality as predictors of progression of diabetic retinopathy. Curr Pharmaceut Design. 2007;13:2699-2712.

49. Kern TS, Barber AJ. Retinal ganglion cells in diabetes. J Pbysiol. 2008;586:4401-4408

50. Meyer-Rüsenberg B, Pavlidis M, Stupp T, Thanos S. Pathological changes in human retinal ganglion cells associated with diabetic and hypertensive retinopathy. Graefes Arch Clin Exp Ophthalmol. 2007;245:1009-1018.

51. Gastinger MJ, Kunselman AR, Conboy EE, Bronson SK, Barber AJ. Dendrite remodeling and other abnormalities in the retinal ganglion cells of Ins2 Akita diabetic mice. Invest Ophthalmol Vis Sci. 2008;49:2635-2642.

52. Kizawa J, Machida S, Kobayashi T, Gotoh Y, Kurosaka D. Changes of oscillatory potentials and photopic negative response in patients with early diabetic retinopathy. Jpn J Opbthalmol. 2006;50: 367-373. 